\title{
Nasal Cavity and Ethmoid Sinus Cancer pT4a TNM Finding v7
}

National Cancer Institute

\section{Source}

National Cancer Institute. Nasal Cavity and Ethmoid Sinus Cancer pT 4a TNM Finding v7. NCI Thesaurus. Code C89108.

Nasal cavity and ethmoid sinus cancer with moderately advanced local disease. Tumor invades any of the following: anterior orbital contents, skin of nose or cheek, minimal extension to anterior cranial fossa, pterygoid plates, sphenoid or frontal sinuses. (from AJCC 7th Ed.) 